\title{
Evaluation of Adsorbents for Removal of Isopropanol from Humid Air
}

\author{
Tim Täffner* ${ }^{, 1}$, Bernd Niemeyer $^{1}$, Angela Puls ${ }^{2}$ and Frieder Dreisbach ${ }^{2}$ \\ ${ }^{1}$ Helmut-Schmidt-University, University of the Federal Armed Forces Hamburg, Process Engineering, Holstenhofweg \\ 85, D-22043 Hamburg, Germany \\ ${ }^{2}$ Rubotherm GmbH, Universitätsstr, 142, D-44799 Bochum, Germany
}

\begin{abstract}
Nowadays sustainable technologies gain in importance. A promising field of activity is the exhaust air treatment by adsorption, especially the removal and recovery of valuable substances like solvents. In this letter three types of adsorbents, being the critical part in technical separation processes by adsorption, are evaluated according to separation of isopropanol from humid air. Isopropanol has been chosen as it is one of the frequently used solvents which need to be separated from humid air in practice. The suitability and performance as well as information about the possible constraints are derived from state of the art measurements and multifaceted analyses of the experimental data. The evaluation is based on physical data, isotherms at different temperatures and for both components, isopropanol and water, as well as on energetic calculations and comparison with values from recent literature.
\end{abstract}

Keywords: Gas, exhaust, solvent, vapor, adsorption, odor, separation, humidity.

${ }^{\#}$ Dedicated to Prof. em. Dr.-Ing. Gerd Brunner for his $70^{\text {th }}$ birthday.

\section{INTRODUCTION}

The separation of pollutants, odorants and valuable substances from ambient air is an omnipresent task. It concerns big exhaust gas flows from industry as well as crafting and households. Process exhaust air which occurs during industrial processing is often treated under various aspects: Valuable substances like solvents may be recovered, pollutants and odorants have to be fully removed in order to fulfil legal specifications and to protect environment and citizens.

The reduction of pollutant and odor emissions caused by handcraft and households is mandatory in order of environmental protection and the integration of business into residential areas in densely populated areas [1,2]. Exhaust gas at ambient conditions contaminated with process-specific compounds which have to be removed is often also loaded with water vapor. The focus of this work is on adsorption, seen as a sustainable separation technology, providing economic and ecologic advantages [3]. The crucial point is the concentrating effect for certain types of vapors, which is exploited by solvent recovery and economic thermal incineration of pollutants. Exemplarily isopropanol was used, because it represents a widely employed solvent and, as a model substance for, organic odorants according to its size, polarity and other physical properties.

It is applied for the extraction and purification of natural products as well as for several cleaning processes in industry, handcraft and households.

Beneath the adsorption of isopropanol, water vapor is considered as adsorptive which is omnipresent and may

*Address correspondence to this author at the Helmut-Schmidt-University, University of the Federal Armed Forces, Hamburg, Faculty of Mechanical Engineering, Institute of Thermodynamics, Holstenhofweg 85, 22043 Hamburg, Germany; Tel: +49/406541-2882; Fax: +49/406541-2008;

E-mail: taeffner@hsuhh.de reduce the separation efficiency of the applied process. The negative influence of water adsorption onto the technical adsorption of solvents is known from specific applications and recent analyses [4-7].

The chosen adsorbents represent possible base materials for technical adsorption processes applicable for industry and handcraft facilities. They represent a preselection of recently developed adsorbents which are designed for the removal of organic compounds by a fixed bed system. Various verified analyses and methods [8-11] are applied in order to evaluate their properties.

\section{EXPERIMENTAL}

For the analysis described within this publication, three different types of adsorbents were selected. Two functionalized mesoporous silica materials denoted as HSU 10 and HSU 11 and a modified zeolite denoted as HSU 50 were chosen as appropriate model structures. All samples were dried for $24 \mathrm{hrs}$ at $60^{\circ} \mathrm{C}$ under vacuum $\left(\mathrm{p}<10^{-2} \mathrm{kPa}\right)$.

For the determination of the specific surface, total pore volume, micropore volume and average pore diameter the complete adsorption and desorption isotherms were measured at $77 \mathrm{~K}$ with nitrogen as adsorbate. All measurements were carried out on a volumetric adsorption analyzer (BELSORP-mini II, BEL Japan INC, Osaka, Japan) in the relative pressure range of $0>p^{*}<0.995$. The flow chart of the device is shown in Fig. (1). The evaluation of the data was performed according to the standard evaluation methods (BET $[12,13]$ and BJH method $[14,15]$ and other standardized procedures e. g. DIN ISO 66135 [16-18]).

The water and isopropanol vapor adsorption measurements were performed at two different temperatures ( $283 \mathrm{~K}$, $296 \mathrm{~K}$ ) on a volumetric vapour adsorption analyzer (BELSORP-aqua ${ }^{3}$, BEL Japan INC, Osaka, Japan) with integrated 

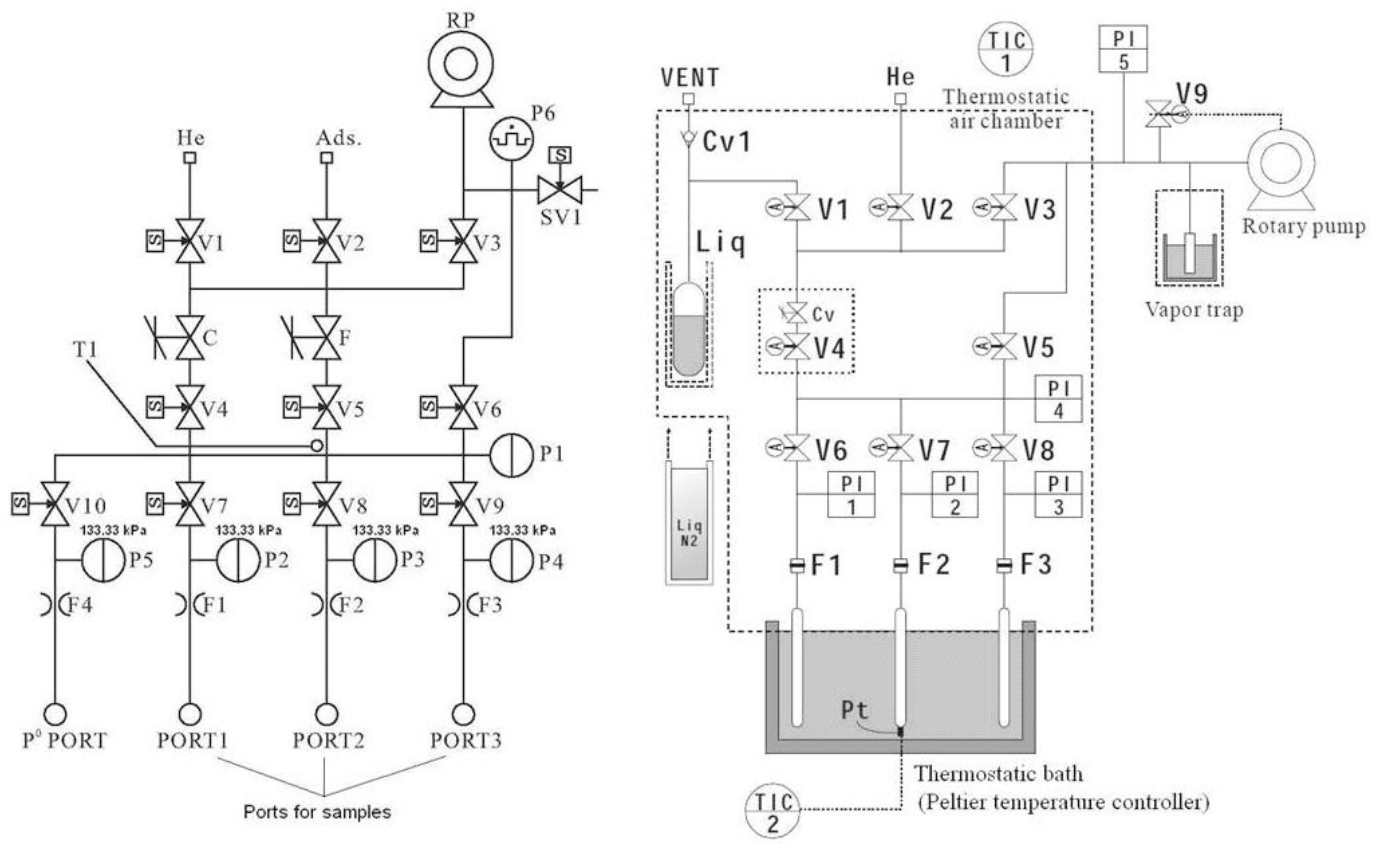

Fig. (1). Flow charts of BELSORP-mini II (left) and BELSORP aqua (right).

degassing facility for liquids in the relative pressure range of $0.05<\mathrm{p} *<0.95$. The flow chart of the instrument is also given in figure 1 (right side). Up to three samples can be measured simultaneously.

Both liquids were degassed several times before the measurement by freezing in liquid nitrogen and evacuation of frozen material. The vaporization temperature was set to $80{ }^{\circ} \mathrm{C}$ for thermostating the vapor pressure cell and the manifold of the instrument. The sample temperature was controlled by a Peltier element and an appropriate thermostatisation? liquid. For the vapor measurements an equilibrium time of $800 \mathrm{sec}$ was used for the complete isotherm, for each measurement cycle all three samples were measured simultaneously at one set of parameters.

\section{RESULTS AND DISCUSSION}

Applying these different experimental methods, data were generated for analyses of the three adsorbents. Table $\mathbf{1}$ presents the physical data of the three adsorbents taken into account within the scope of this study. All adsorbents show a comparable specific surface $A_{\text {BET }}$ of at least $326 \mathrm{~m}^{2} / \mathrm{g}$. But there are considerable differences according to the specific pore volume $\mathrm{V}_{\text {Pore }}$ and the pore size distribution. While HSU 10 and HSU 11 show large pore volumes and mesopores,
HSU 50 reveals a significant proportion of micropores and therefore a smaller mean pore diameter $\mathrm{D}_{\mathrm{P}}$ of $0.9 \mathrm{~nm}$.

Furthermore adsorption isotherms for isopropanol and water have been determined at temperatures of $283 \mathrm{~K}$ and $296 \mathrm{~K}$. This reveals information on adsorption equilibria in a technically relevant spectrum of temperature and concentration for both competitive adsorptives. Moreover isosteric heats of adsorption were calculated in order to estimate affinities between adsorbents and adsorptives under various conditions and to provide criteria for the selection of adsorbents for specific technical applications.

Fig. (2) shows isotherms for isopropanol at $296 \mathrm{~K}$ for all three adsorbents. According to the IUPAC classification [19, 20] type IV can be identified for HSU 10, HSU 11 and HSU 50. This is reasonable considering the aforementioned pore structure of the adsorbents. Thus all analyzed adsorbents show a plateau in loading of approximately $1.7 \mathrm{mmol} / \mathrm{g}$ from $10 \%$ to $45 \%$ saturation.

At high saturation conditions of above $90 \%$ the samples reach different saturation loadings of $12.7 \mathrm{mmol} / \mathrm{g}$ for HSU $10,9.5 \mathrm{mmol} / \mathrm{g}$ for HSU 11 and $2.3 \mathrm{mmol} / \mathrm{g}$ for HSU 50, respectively. An important aspect is the large hysteresis in the isotherms on the adsorbents HSU 10 and HSU 11. This

Table 1. Physical Data According to the Evaluated Adsorbents

\begin{tabular}{|c|c|c|c|c|}
\hline \multirow{2}{*}{ Adsorbent } & $\mathbf{A}_{\mathbf{B E T}}$ & $\mathbf{V}_{\text {Pore }}$ & $\mathbf{V}_{\text {MicroP }}$ & $\mathbf{D}_{\mathbf{P}}$ \\
\cline { 2 - 5 } & {$\left[\mathbf{m}^{2} / \mathbf{g}\right]$} & {$\left[\mathbf{c m}^{3} / \mathbf{g}\right]$} & - & 10.6 \\
\hline \hline HSU 10 & 348 & 1.151 & 0.139 & 0.9 \\
\hline HSU 50 & 326 & 0.273 & - & 6.2 \\
\hline HSU 11 & 389 & 0.796 & & \\
\hline
\end{tabular}




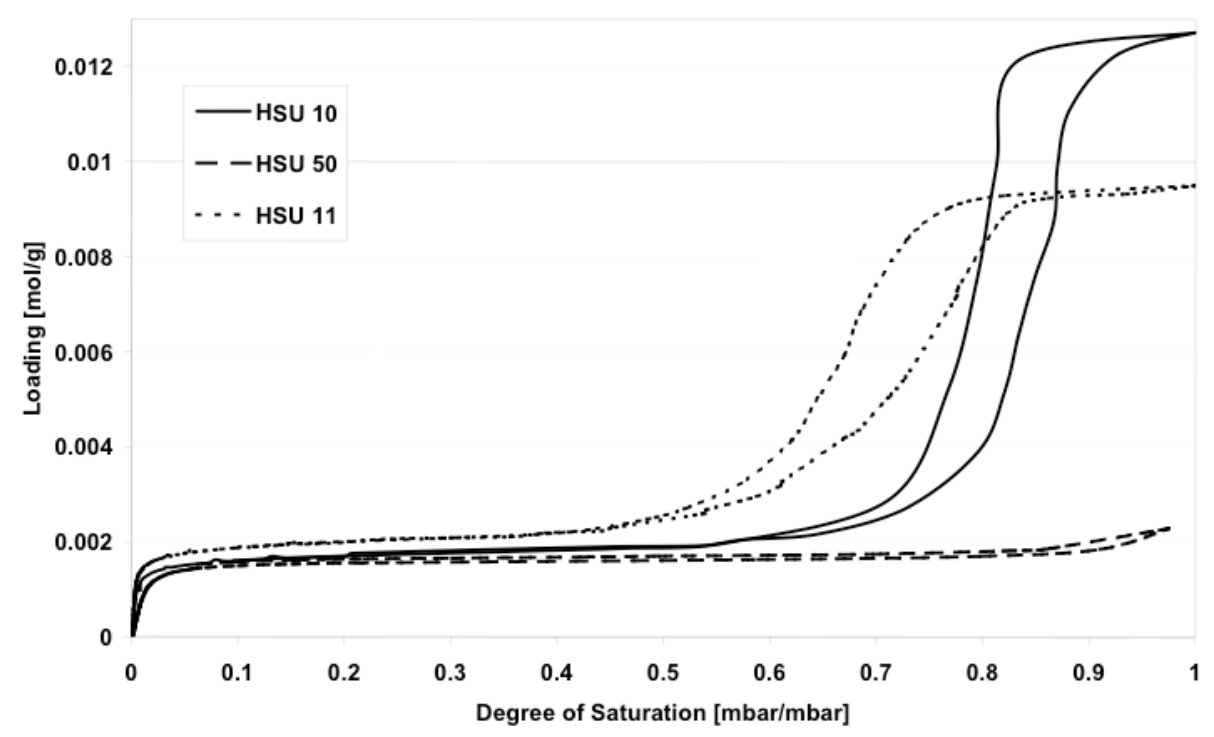

Fig. (2). Isothermes for isopropanol on adsorbents HSU 10, HSU 11 and HSU 50 at $296 \mathrm{~K}$.

has to be considered while handling the desorption of isopropanol by increasing temperature, lowering concentration or pressure, respectively. Contrary to that the isotherm on the HSU 50 sample shows a much less pronounced hysteresis than expected for a predominantly microporous material.

The initial part of the isotherms at a saturation below 10 $\%$ is depicted in Fig. (3). The small outlying peaks are caused by randomly measuring uncertainties during the measurement process within the low pressure range. Low concentrations of isopropanol are expected at technical applications in industry. Therefore this part of the isotherms is of special interest. Hence HSU 11 reveals the highest loading at every concentration in this area.

In contrast to isopropanol as adsorptive, water leads to different types of isotherms as depicted in Fig. (4).

For the adsorbents HSU 10, HSU 11 and HSU 50 isotherms being rather of type $\mathrm{V}$ can be identified. Pore con- densation effects appear strongly as well again for HSU 10 and HSU 11 at $80 \%$ and $70 \%$ of saturation, respectively. Furthermore the maximum loadings reached at full saturation are significantly higher compared to those with isopropanol. Thus the operation conditions of adsorbents have to be analyzed carefully, as water pore condensation effects appear within a few percent of saturation.

At all states of saturation HSU 50 distinguishes itself by lower water loadings. Again, only a very small hysteresis can be observed for this material, indicating the low mesopore volume of HSU 50.

From the saturation loadings the pore filling degree $\Xi$ is revealed and presented in Table 2 , proving, that the pores of HSU 10 and HSU 11 are nearly filled with water as well as isopropanol at the given conditions. In contrast HSU 50 shows a significant higher degree of pore filling for isopropanol compared to water, but a lower degree of pore filling in general. A hydrophobic surface structure and a ratio of

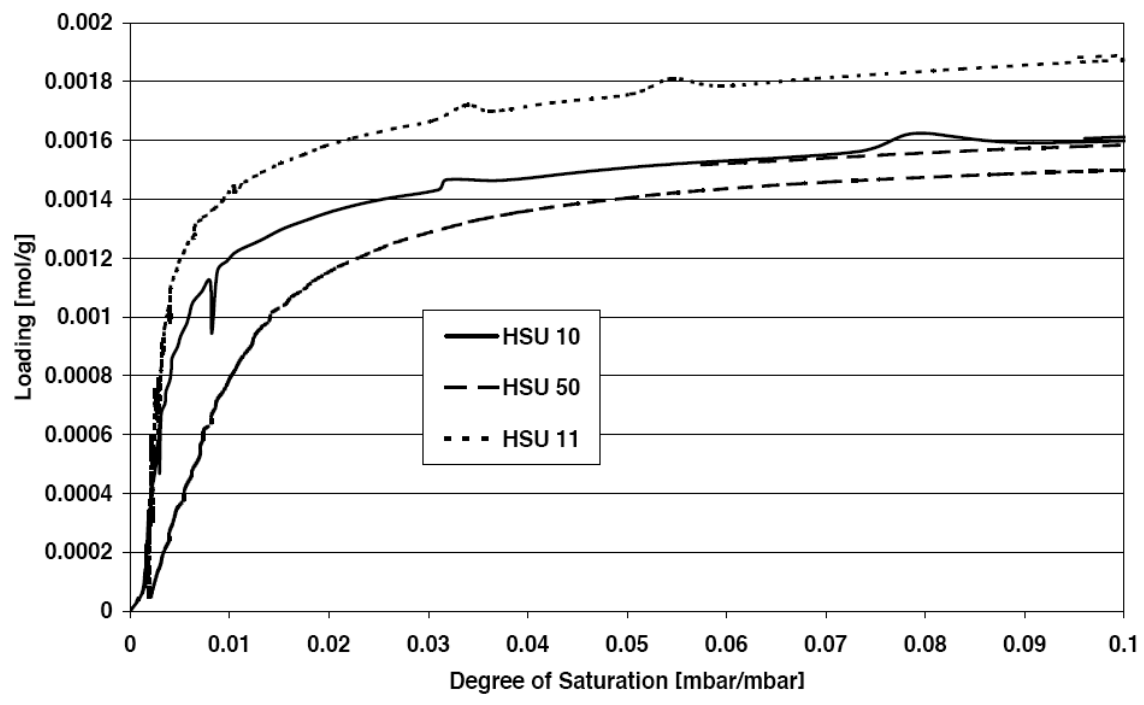

Figure 3: Magnified part from figure 2, loading at low saturation. 


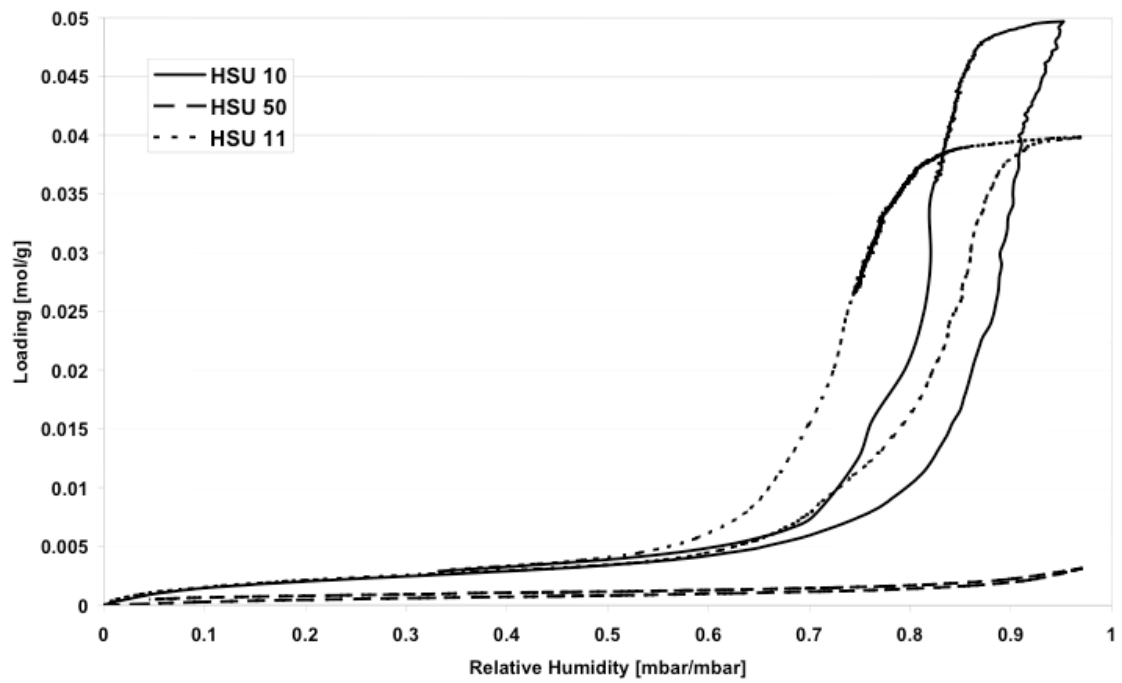

Fig. (4). Isothermes for water and adsorbents HSU 10, HSU 11 and HSU 50 at $296 \mathrm{~K}$.

Table 2. Pore Filling at Maximum Saturation for Isopropanol (iPrOH) and Water at $296 \mathrm{~K}$

\begin{tabular}{|c|c|c|c|c|c|}
\hline & $\mathbf{V}_{\text {Pore }}$ & $\mathbf{V}_{\text {max }, \text { PrOH }}$ & $\mathbf{\Xi}_{\text {iPrOH }}$ & $\mathbf{V}_{\text {max, water }}$ & $\boldsymbol{\Xi}_{\text {water }}$ \\
\cline { 2 - 6 } Adsorbent & {$\left[\mathbf{c m}^{3} / \mathbf{g}\right]$} & {$\left[\mathbf{c m}^{3} / \mathbf{g}\right]$} & {$[\%]$} & 0.895 & 78 \\
\hline \hline HSU 10 & 1.151 & $0.979]$ & 0.057 & 21 \\
\hline HSU 50 & 0.273 & 0.177 & 65 & 0.717 & 90 \\
\hline HSU 11 & 0.796 & 0.732 & 92 & & 78 \\
\hline
\end{tabular}

$51 \%$ micropores rated by pore volume $\left(\mathrm{V}_{\text {Pore }}\right)$ explains these observations.

For both adsorptives the structure of the isotherms does not change while decreasing the temperature to $283 \mathrm{~K}$. As an example we show here the adsorption of isopropanol on HSU 10 at the two different temperatures in Fig. (5).

The loadings and the shape of the isotherm generally remain unchanged. However, at lower temperatures the satura- tion is reached at lower absolute pressures due to the change in saturation vapour pressure. For representations using the degree of saturation (relative humidity), the abscissa of the isotherms almost coincides with the usually small change in loading due to temperature change.

In order to describe the affinity between isopropanol and water and the adsorbents, the isosteric adsorption heat $\mathrm{Q}_{\mathrm{ST}}$ is calculated applying the Clausius-Clapeyron equation (1):

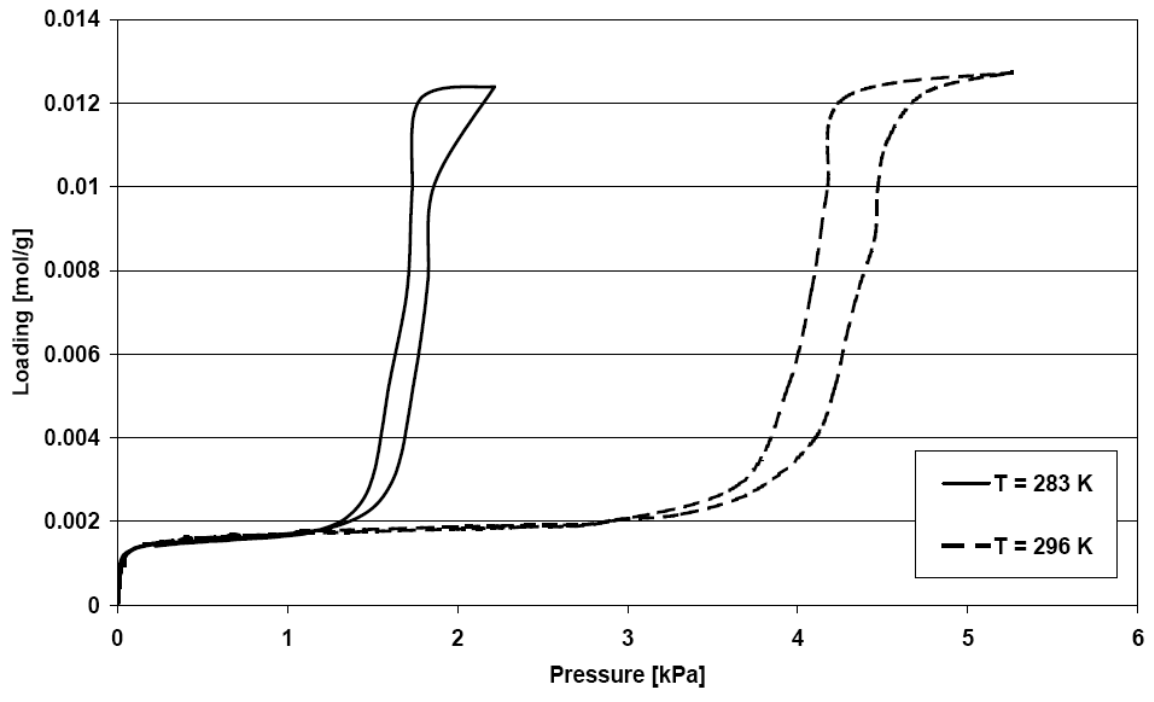

Fig. (5). Isothermes for isopropanol and HSU 10 at $283 \mathrm{~K}$ and $296 \mathrm{~K}$, respectively. 
$\left(\frac{\partial \ln p}{\partial T}\right)_{q}=\frac{Q_{S T}}{R T^{2}}$

or equivalent:

$\left(\frac{\partial \ln p}{\partial 1 / T}\right)_{q}=-\frac{Q_{S T}}{R}$

For the calculation it is assumed that the liquid volume of the adsorbate is significantly smaller than its vapour. Furthermore the ideal gas law is supposed to be in force for the gas phase. Equation (2) as equivalent expression is presented for the sake of completeness. It is preferred as Arrheniusform in order to present $\mathrm{Q}_{\mathrm{ST}}$ as slope of the graph at constant loading within the $\mathrm{p}-1 / \mathrm{T}$-diagram.

The determination of $\mathrm{Q}_{\mathrm{ST}}$ is based on the two adsorption isotherms at different temperatures which results in the graphs presented in Fig. (6). The calculated data are linked to their respective loadings.

It can be seen that the adsorption is an exothermal process. The adsorption of water is for all three adsorbents less exothermal than the adsorption of isopropanol. The positive values of the isosteric adsorption heat for water at lowest loadings represent an artefact based on measurement uncertainties amplified by the above mentioned methods of data analyses.

QST represents the sum of the heat of condensation $\Delta \mathrm{H}_{\mathrm{v}}$ and the binding energy $\Delta \mathrm{H}_{\mathrm{b}}$ :
$Q_{S T}=\Delta H_{b}+\Delta H_{v}$

$\Delta \mathrm{H}_{\mathrm{v}}$ is not dependant on the loading, but on temperature and pressure which are kept constant. Hence $\Delta \mathrm{H}_{\mathrm{v}}$ is calculated to $44.1 \mathrm{~kJ} / \mathrm{mol}$ for water [21] and $45.7 \mathrm{~kJ} / \mathrm{mol}$ for isopropanol [22] at $296 \mathrm{~K}$. The graphs in Fig. (6) reveal that Q with the value of $\Delta \mathrm{H}_{\mathrm{v}}$ at high loadings. Hence, at high degrees of saturation or high loadings respectively condensation of the vapour onto the inner pore surface takes place. In this case the interaction between the surface of the adsorbent and the adsorptive molecules has only a very minor influence:

$\lim _{q \rightarrow q_{\max }}\left(Q_{S T}\right)=\Delta H_{v}$

thus, implementing (3):

$\lim _{q \rightarrow q_{\max }}\left(\Delta H_{b}\right)=0$

At very low loadings an incomplete monolayer of adsorbate can be assumed, hence $\Delta \mathrm{H}_{\mathrm{b}}$ strongly affects $\mathrm{Q}_{\mathrm{ST}}$ following equation (3). Thus, the affinity of the adsorbateadsorbent-bond can be estimated based on the values at low loadings presented in Fig. (6). Hence the binding energy for all three adsorbents is predominantly negative for the interaction with isopropanol and positive with water. The isosteric heat of adsorption for both adsorptives converges to their heat of condensation at high loadings. Thus, we find that the affinity of water increases with loading, and relative humidity, respectively. At low loadings the isosteric heat of adsorption is much smaller than the heat of condensation.
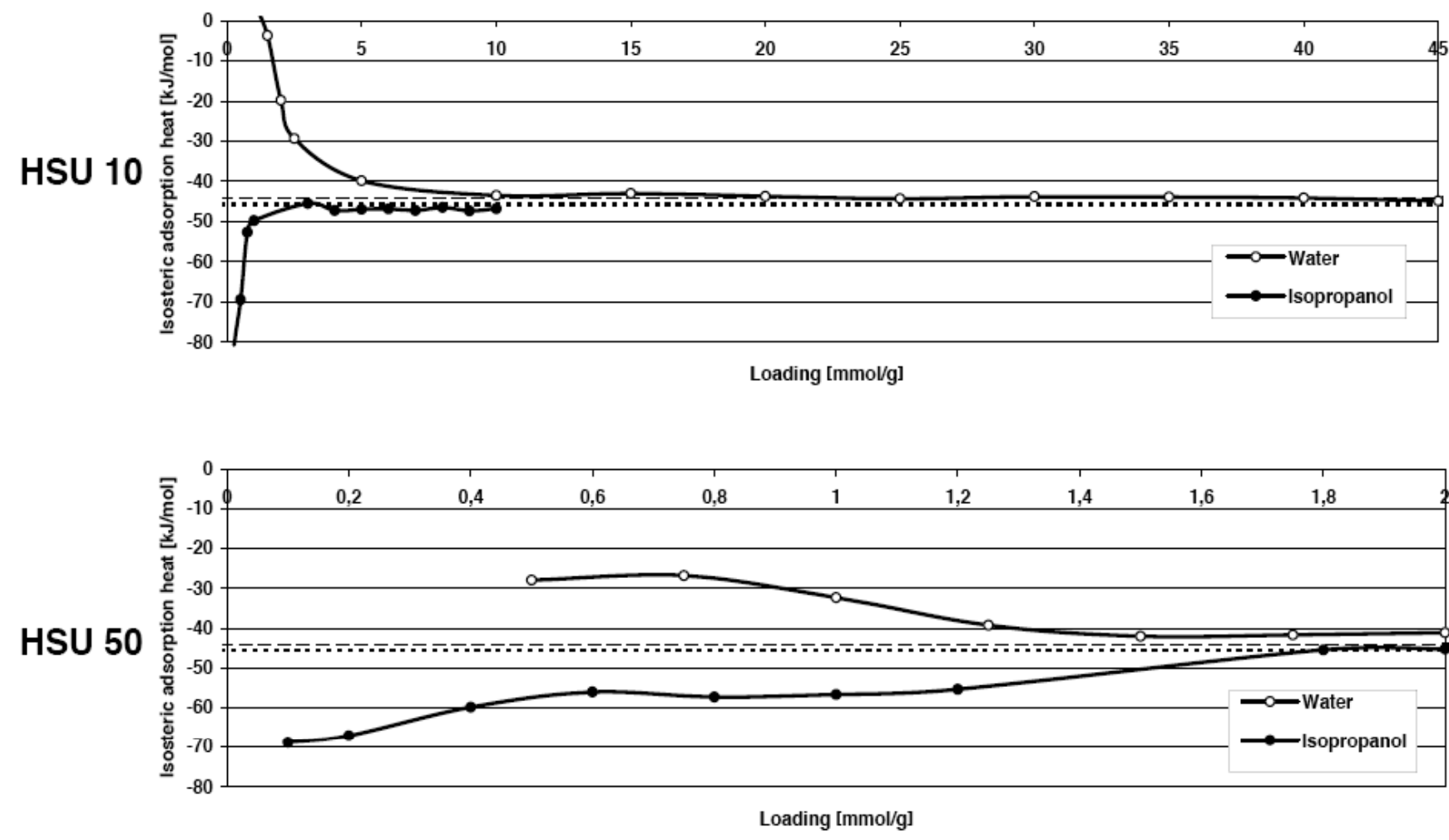

Fig. (6). Isosteric adsorption heats for HSU 10, HSU 50 and HSU 11 for water and isopropanol, heats of condensation for water (dashed lines) and isopropanol (dotted lines). 
This is due to the hydrophobic nature of the surface of the HSU 10 and HSU 11 adsorbents. In contrary, the affinity between isopropanol and the adsorbent surface decreases with increasing loading (relative saturation). At low loadings it is much stronger than the heat of condensation [23, 24].

\section{CONCLUSION}

Nitrogen, water and isopropanol adsorption were measured on three specific and partly functionalized adsorbent materials. All three matters show a fundamental suitability for the removal of isopropanol from exhaust air. The HSU 10, HSU 50 and HSU 11 materials adsorb more than 1 $\mathrm{mmol} / \mathrm{g}$ of adsorbent material at a few per cent of saturation. This corresponds to a mass loading of at least $6 \%(\mathrm{w} / \mathrm{w})$. For very low concentrations below $1 \%$ of saturation of isopropanol, HSU 11 is identified as the material with the highest initial slope of the isotherm. At concentrations between $10 \%$ and $50 \%$ of saturation HSU 11 shows a slightly higher loading. While the microporous material HSU 50 reveals almost no pore condensation effects at high loadings, HSU 10 and HSU 11 present a strong increase in the loading at 80 $\%$, and $70 \%$ of saturation, respectively due to pore condensation in their mesoporous framework.

In contrast to this, isotherms for water adsorptionIn contrast to this, isotherms for water adsorption can be more strongly distinguished. HSU 50 has slowly increasing loadings up to $3 \mathrm{mmol} / \mathrm{g}$, which corresponds to a mass loading of $5.4 \%(\mathrm{w} / \mathrm{w})$, while HSU 10 and HSU 11 reach after a nearly linear increase a value of $4 \mathrm{mmol} / \mathrm{g}$ at $50 \%$ of relative humidity. Pore condensation takes place in these materials at $85 \%$, and $75 \%$ of relative humidity, respectively.

While HSU 10 and HSU 11 show very high degrees of pore filling for both, isopropanol and water, HSU 50 reveals a significant higher degree of pore filling for isopropanol compared to that of water.

From the isotherm data at different temperatures isosteric adsorption heats were calculated and presented. The value of the isosteric adsorption heat for water is at low loadings smaller than the heat of condensation, thus indicating the hydrophobic nature of the surface of the adsorbents. The peak values are consistent with recent findings from litertature [23-25]. For isopropanol the opposite is true. Here the isosteric adsorption heat decreases with increasing loading. This finding is in good agreement with comparable systems presented by Muminov [26] and Taraba [27]. For both adsorptive vapours the heat of adsorption converges into the condensation heat at high loadings or degrees of saturation, respectively [23, 24].

The usage of Dubinin-Astakhov-model for the description of these pore condensation effects and in order to estimate isosteric adsorption heat has been reported recently by Pires et al., [28]. The derived results are according to the regime in good agreement with the results presented in this paper. The presented adsorbents show a significant higher affinity towards isopropanol than to metal alizarinate complexes [29].

Thus the determined materials reveal different characteristic properties and are suitable for various fields of application. These range from the recovery of a solvent like isopro- panol from dry and humid air to the cleaning of exhaust gas by removal of organic compounds.

It is emphasized, that this multifaceted analyses is based directly on experimental results created using commercially available, state of the art volumetric equipment. The next step has to be the experimental investigation of the competitive adsorption of mixed isopropanol and water vapour applying an even more sophisticated experimental setup.

\section{ACKNOWLEDGEMENTS}

These results were achieved as part of the project "Odour Control - lowering odour for the enhancement of the acceptability of the food processing companies in urban areas in Germany and China", which is funded by the German Federal Ministry of Education and Research (BMBF) under support code $0330796 \mathrm{~A}$ and $0330796 \mathrm{H}$ under the guidance of our lead partner from the Projektträger Jülich Mr. Weber. Sincere thanks are given to all contributors.

\section{SYMBOLS}

$\begin{array}{llll}{\left[\mathrm{A}_{\mathrm{BET}}\right]} & = & \mathrm{m}^{2} \mathrm{~g}^{-1} & \text { Specific surface } \\ {\left[\mathrm{D}_{\mathrm{P}}\right]} & = & \mathrm{nm} & \text { Mean pore diameter } \\ {\left[\Delta \mathrm{H}_{\mathrm{b}}\right]} & = & \mathrm{kJmol}^{-1} & \text { Binding energy } \\ {\left[\Delta \mathrm{H}_{\mathrm{v}}\right]} & = & \mathrm{kJmol}^{-1} & \text { Heat of condensation } \\ {[\mathrm{p}]} & = & \mathrm{mbar} & \text { Pressure } \\ {[\mathrm{p} *]} & = & - & \text { Relative pressure } \\ {\left[\mathrm{Q}_{\mathrm{ST}}\right]} & = & \mathrm{kJmol}^{-1} & \text { Isosteric adsorption heat } \\ {[\mathrm{R}]} & = & \mathrm{Jmol}^{-1} \mathrm{~K}^{-1} & \text { Universal gas constant } \\ {[\mathrm{T}]} & = & \mathrm{K}^{3} & \text { Temperature } \\ {\left[\mathrm{V}_{\text {MicroP }}\right]} & = & \mathrm{cm}^{3} \mathrm{~g}^{-1} & \text { Specific micropore volume } \\ {\left[\mathrm{V}_{\text {Pore }}\right]} & = & \mathrm{cm}^{3} \mathrm{~g}^{-1} & \text { Specific pore volume } \\ {[\varphi]} & = & - & \text { Degree of saturation } \\ {[\Xi]} & = & \% & \text { Degree of pore filling }\end{array}$

\section{REFERENCES}

[1] D. Shusterman, "Odor-associated health complaints: competing explanatory models", Chem. Senses, vol. 26, pp. 339-343, 2001

[2] D.J. Paustenbach and S.H. Gaffney, "The role of odor and irritation, as well as risk perception, in the setting of occupational exposure limits”, Int. Arch. Occup. Environ Health, vol. 79, pp. 339 342, 2006.

[3] H. Rosenfeld, S. Peper, T. Täffner, M. Kötke, M.A. Fonka, H. Temme and B. Niemeyer, "Effektive stofftrennung in gas- und flüssigphase durch selektive adsorption", Chem. Ing. Tech., vol. 83, pp. 1229-1236, 2011, DOI:10.1002/cite.201000178.

[4] E.M. Pakhlov, E.F. Voronin, M.V. Borysenko and G.R. Yurchenko, "Study of water, methanol and isopropanol adsorption on the surface of titanosilicas of different structure", J. Therm. Anal. Cal., vol. 62, pp. 395-399, 2000.

[5] M.L. Gubkina, N.S. Polyakov, G.A. Petukhova, O.V. Kalmykova and E.A. Ustinov, "Adsorption of vapor mixtures of water and organic substance on acrtivated carbons", Russ. Chem. Bull., vol. 50, pp. 595-598, 2001.

[6] D.K.W. Wang and C.C. Austin, "Determination of complex mixtures of volatile organic compounds in ambient air: an overview", Anal. Bioanal. Chem., vol. 386, pp. 1089-1098, 2006.

[7] T. Täffner, M. Birkenseer, Y. Liu, M. Bischoff and B. Niemeyer, "Selektive Adsorbentien zur Optimierung der Abluftbehandlung in lebensmittelverarbeitenden Betrieben“, Chem. Ing. Tech., vol. 82, pp. 2171-2178, 2010, DOI:.10.1002/cite.201000034. 
[8] S.Z. Muminov, D.B. Gulyamova and E.A. Seitova, "Adsorption of toluene vapors on some organomontmorillonites", Colloid J., vol. 65, pp. 648-651, 2003.

[9] F. Dreisbach, T. Täffner and B. Niemeyer, "Application-oriented Assessment of Optimized Adsorbents for H2S-Removal", in: B. Niemeyer, R.G. Berger, K. Krüger, G. Matz, R. Otterpohl, R. Stegmann (eds.), Odour Control, Hamburger Berichte 36, Verlag Abfall aktuell, Stuttgart, FRG, 2010, ISBN 978-3-9812867-4-8, 69 -81 .

[10] Y.-S. Bae, J.-H. Moon, H. Ahn and C.-H. Lee, "Effects of adsorbate properties on adsorption mechanism in a carbon molecular sieve”, Korean J. Chem. Eng., vol. 21, pp. 712-720, 2004.

[11] V.M. Gun'ko, "Competitive adsorption", Theor. Exp. Chem., vol. 43, pp. 139-183, 2007.

[12] S. Brunauer, P.H. Emmett and E. Teller, "Adsorption of gases in multimolecular layers", J. Am. Chem. Soc., vol. 60, pp. 309-319, 1938.

[13] H. Rosenfeld, S. Peper, T. Täffner, M. Kötke, M.A. Fonka, H. Temme and B. Niemeyer, "Effektive Stofftrennung in Gas- und Flüssigphase durch selektive Adsorption", Chem. Ing. Tech., vol. 83, pp. 1229-1236, 2011, DOI:10.1002/cite.201000178.

[14] E.P. Barrett, L.G. Joyner and P.P. Halenda, "The determination of pore volume and area distributions in porous substances, I. Computations from nitrogen isotherms", J. Am. Chem. Soc., vol. 73, pp. 373-380, 1951.

[15] DIN ISO 66134 Bestimmung der Porengrößenverteilung und der spezifischen Oberfläche mesoporöser Feststoffe durch Stickstoffsorption, Beuth Verlag, Berlin, Germany 2007.

[16] DIN ISO 66135 Mikroporenanalyse mittels Gasadsorption, Beuth Verlag, Berlin, Germany 2007.

[17] M. Thommes, "Physical adsorption characterization of nanoporous materials", Chem. Ing. Tech., vol. 82, pp. 1059-1073, 2010.

[18] J. Rouquerol, P. Llewellyn and F. Rouquerol, "Is the BET equation applicable to microporous adsorbents?", Stud. Surf. Sci. Catal., vol. 160, pp. 49-56, 2007.

[19] S. Brunauer, L.S. Deming and W.S. Deming, "On a theory of the van der Waals adsorption of gases" J. Amer. Chem. Soc., vol. 62, pp. 1723-1732, 1940.
[20] K.S.W. Sing, D.H. Everett, R.A.W. Haul, L. Moscou, R.A. Pierotti, J. Rouquerol and T. Siemieniewska, "Reporting physisorption data for gas/solid systems with special reference to the determination of surface area and porosity", Pure Appl. Chem., vol. 57, pp. 603-619, 1985.

[21] VDI-Wärmeatlas, (Eds: VDI-Gesellschaft), Springer Verlag, Berlin, Germany 2006.

[22] V. Majer and V. Svoboda, Enthalpies of vaporization of organic compounds: A critical review and data compilation, Blackwell Scientific Publications, Oxford, Great Britain, 1985.

[23] X.L. Wang, H.T. Chua and L.Z. Gao, "A thermogravimetric analyzer for condensable gas adsorption under conditions", J. Therm. Anal. Calorim., vol. 90, pp. 935-940, 2007.

[24] H. Demir, M. Mobedi and S. Ülku, "Microcalorimetric investigation of water vapor adsorption on silica gel", J. Therm. Anal. Calorim., published online, DOI 10.1007/s10973-011-1395-y, pp. 1-8, 2011.

[25] K.F. Loughlin, "Water isotherm models for 4A (NaA) zeolite", Adsorption, vol. 15, pp. 337-353, 2009.

[26] S.Z. Muminov, "Temperature dependence of methanol adsorption on sodium and polyhydroxyaluminum montmorillonites", Colloid J., vol. 73, pp. 253-256, 2011.

[27] B. Taraba, "Adsorption heats of phenol on activated carbon using adapted method of immersion calorimetry", J. Therm. Anal. Calorim., published online, DOI 10.1007/s10973-011-1523-8, pp. 1-4, 2011

[28] J. Pires, M.L. Pinto and J.M. Guil, "Heats of adsorption from the Dubinin-Astakhov model applied to the characterization of pillared interlayered clays (PILCs)", Adsorption, vol. 17, pp. 287-292, 2011.

[29] Y.G. Slizhov and M.A. Gavrilenko, "Separation of phenols, alcohols, and alkylbenzenes by gas chromatography on adsorption layers of copper and nickel alizarinates", Russ. J. Phys. Chem., vol. 80, pp. 489-490, 2006

Received: September 18, 2011

Revised: October 25, 2011

Accepted: November 02, 2011

(C) Täffner et al.; Licensee Bentham Open.

This is an open access article licensed under the terms of the Creative Commons Attribution Non-Commercial License (http://creativecommons.org/licenses/by-nc/3.0/) which permits unrestricted, non-commercial use, distribution and reproduction in any medium, provided the work is properly cited. 